\title{
Electronic Effect in Methanol Dehydrogenation on Pt Surfaces: Potential Control during Methanol Electrooxidation
}

\author{
Joonhyeon Kang, Seunghoon Nam, Yuhong Oh, Hongsik Choi, Sungun Wi, Byungho Lee, \\ Taehyun Hwang, Saeromi Hong, and Byungwoo Park*
}

WCU Hybrid Materials Program, Department of Materials Science and Engineering, Research Institute of Advanced Materials, Seoul National University, Seoul 151-744, Korea

Supporting Information

ABSTRACT: Establishing a relationship between the catalytic activity and electronic structure of a transition-metal surface is important in the prediction and design of a new catalyst in fuel cell technology. Herein, we introduce a novel approach for identifying the methanol oxidation reactions, especially focusing on the effect of the $\mathrm{Pt}$ electronic structure on methanol dehydrogenation. By systematically controlling the electrode potential, we simplified the reaction paths, excluding other unfavorable effects, and thereby obtained only the methanol dehydrogenation activity in terms of the electronic structure of the Pt surface. We observed that the methanol dehydrogenation activity of Pt decreases when the position of the d-band center relative to the Fermi level is lower, and this fundamental relation provides advanced insight into the design of an optimal catalyst as the anode for direct methanol fuel cells.

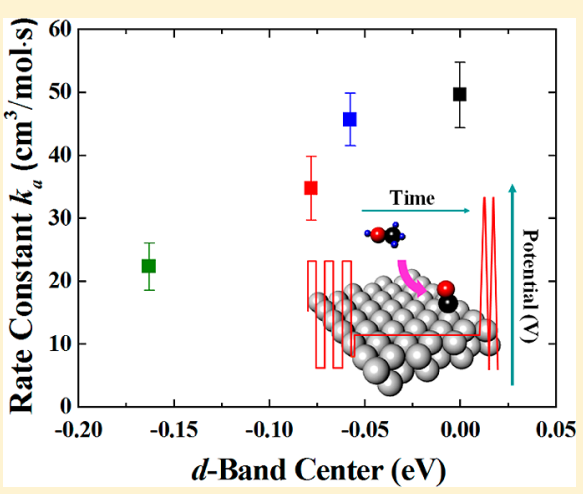

SECTION: Energy Conversion and Storage; Energy and Charge Transport

$\mathrm{F}$ el cells are promising alternative power generation sources to conventional combustion-based ones, capable of environmentally friendly energy conversion. Polymer electrolyte membrane fuel cells (PEMFCs) and direct methanol fuel cells (DMFCs) are the key technologies of low-temperature cells for various applications such as electric vehicles, portable electronic devices, and so forth. ${ }^{1-7}$

Unfortunately, current state-of-the-art catalysts are mainly platinum-based, often too expensive for large-scale commercialization. $^{8-13}$ To overcome this barrier, researchers have tried to establish the fundamental rule governing the activity of catalysts. With progresses in density functional theory (DFT) calculations, Nørskov and several co-workers proposed the dband center relative to the Fermi level as a descriptor for the reactivity of a transition-metal surface. ${ }^{14-20}$ According to this model, the bond strength is characterized by the filling of the antibonding states formed between adsorbate states and metal $\mathrm{d}$ states. Because this filling is given by the energy of the antibonding states relative to the Fermi level, the position of the d-band center relative to the Fermi level is directly related to the adsorption energies and activation barriers in catalytic reactions. The higher the position of the d-band center relative to the Fermi level, the more vacant the antibonding states, which leads to a stronger bond between the adsorbate and the metal surface. ${ }^{14,15,17,20}$ Actually, this model has successfully represented various catalytic reactions, and on the basis of experimentally measured values, many approaches have directly linked catalytic activity with the electronic structures of transition-metal surfaces. ${ }^{21-29}$
However, in the case of the methanol oxidation reaction (MOR), the access to the pure electronic effect has been blocked due to many limitations such as the disturbance of the bifunctional mechanism, ${ }^{30-33}$ complex reaction paths, ${ }^{34-39}$ ensemble-site requirements, ${ }^{31,40-42}$ and so forth. These limitations originate from the intrinsic complexity of methanol oxidation mechanisms. By conventional approaches, it is impossible to observe the electronic effect on the catalytic activity in methanol oxidation.

In this research, we introduce a new strategy for understanding catalytic reactions in terms of electronic structures. Generally, the MOR on Pt can be described by three steps ${ }^{30,34,38,43}$ when passing through the $\mathrm{CO}_{\mathrm{ad}}$ intermediate

$$
\begin{aligned}
& \mathrm{CH}_{3} \mathrm{OH} \rightarrow \mathrm{CO}+4 \mathrm{H}^{+}+4 \mathrm{e}^{-} \\
& \mathrm{H}_{2} \mathrm{O} \rightarrow \mathrm{OH}+\mathrm{H}^{+}+\mathrm{e}^{-} \\
& \mathrm{CO}+\mathrm{OH} \rightarrow \mathrm{CO}_{2}+\mathrm{H}^{+}+\mathrm{e}^{-}
\end{aligned}
$$

Because the $\mathrm{CO}$ oxidation processes (eqs 2 and 3 ) are mainly governed by bifunctional effects and not by the electronic structure when a second component is used with $\mathrm{Pt},{ }^{44,45}$ these processes were separated by sensitive potential control. To focus on the methanol dehydrogenation reaction (eq 1), the

Received: July 12, 2013

Accepted: August 9, 2013

Published: August 9, 2013 
voltage was held at $0.3 \mathrm{~V}$ (versus the reversible hydrogen electrode (RHE)), where methanol is decomposed to $\mathrm{CO}$ without any other reactions. Further reaction does not occur because $\mathrm{Pt}$ is unable to activate water (eq 2), and $\mathrm{CO}_{2}$ cannot be formed until $\sim 0.45 \mathrm{~V}^{41,46-48}$ Also, in the potential range below $0.35 \mathrm{~V}$, the reaction path can be simplified as a sole reaction pathway forming $\mathrm{CO}_{\mathrm{ad}}$ on the $\mathrm{Pt}$ surface without other possible routes that lead to the formation of soluble product species. ${ }^{34}$ Therefore, we can successfully obtain the adsorbed $\mathrm{CO}$ as the final product, not as the reaction intermediate, in this case.

We also excluded the ensemble site effect that hinders the investigation of the electronic effect in an alloy system like $\mathrm{PtRu}$ by using amorphous metal phosphate $\left(\mathrm{FePO}_{4}\right)$ as the support material in the modification of the electronic structure according to the Fermi energy difference. ${ }^{49}$ In our previous research, we have observed that core-level binding energies of $\mathrm{Pt}$ or Au nanoparticles vary with the nearby amorphous metal phosphate, and this material is also known as a suitable transfer medium for protons, hydroxyl ions, water, methanol, and oxygen. ${ }^{50-56}$

Although $\mathrm{Ru}$ or other components are alloyed with $\mathrm{Pt}$ to enhance the CO oxidation process, ${ }^{1,3,9,30-33,41}$ the methanol dehydrogenation rate is still insufficient for the practical application of DMFCs. Therefore, optimum catalysts should be designed by optimizing each aspect, methanol dehydrogenation and $\mathrm{CO}$ oxidation. In this Letter, our approach focuses on the methanol dehydrogenation reaction that leads to the formation of $\mathrm{CO}_{\mathrm{ad}}$, and the results are discussed in terms of the d-band center model. ${ }^{14-17}$ Other reactive intermediates ( $\mathrm{HCOO}^{*}$ or $\mathrm{HCHO}^{*}$ ) or soluble species are not significant in the potential range of interest. ${ }^{34}$ This is the first experimental report on the direct correlation between dehydrogenation activity and the d-band center of a transition metal during the MOR. Our novel finding for the electronic effect in $\mathrm{CO}$ production from methanol can furnish valuable insight into the development of a new catalyst for DMFC.

$\mathrm{Pt}$ nanoparticles having different positions of the d-band center were prepared by varying the sputtering rate of $\mathrm{FePO}_{4}$ with the sputtering rate of $\mathrm{Pt}$ fixed (cosputtering). Before measuring the methanol dehydrogenation activity, we first identified the crystal structure, grain size, and surface orientation of each sample. X-ray diffraction (Figure S2, SI) confirmed polycrystalline $\mathrm{Pt}$ phases embedded in the amorphous $\mathrm{FePO}_{4}$. From the Scherrer equation of $\Delta k$ versus $k$ (the scattering vector $k=(4 \pi / \lambda) \sin \theta$ ), the grain size of $\mathrm{Pt}$ was in the range of $6.8-12.7 \mathrm{~nm}$ for the pure $\mathrm{Pt}$ and $\mathrm{Pt} /$ $\mathrm{FePO}_{4}$ nanocomposites (Table 1). The size decreased with the increased sputtering power of $\mathrm{FePO}_{4}$. However, these are beyond the range where the catalytic activity is strongly sensitive to the Pt nanoparticle size. ${ }^{57-64}$

Table 1. Grain Size of Crystalline Pt at Various Sputtering Powers of $\mathrm{FePO}_{4}$, Obtained from the $\Delta k$ versus $k$ Plot of Figure S2 (SI)

\begin{tabular}{lc}
\multicolumn{1}{c}{ sample } & grain size $(\mathrm{nm})$ \\
$\mathrm{Pt}$ & $12.3 \pm 1.7$ \\
$\mathrm{Pt} / \mathrm{FePO}_{4}(30 \mathrm{~W})$ & $12.7 \pm 1.2$ \\
$\mathrm{Pt} / \mathrm{FePO}_{4}(60 \mathrm{~W})$ & $7.6 \pm 0.4$ \\
$\mathrm{Pt} / \mathrm{FePO}_{4}(90 \mathrm{~W})$ & $6.8 \pm 0.4$
\end{tabular}

From the adsorption and desorption of hydrogen, we measured the active surface areas of $\mathrm{Pt}$ and also confirmed no significant change in $\mathrm{Pt}$ orientation (Figure S1, SI). Furthermore, it was observed that the amorphous $\mathrm{FePO}_{4}$ does not participate in the MOR (Figure S3, SI), only acting as an electronic-tuning component for Pt by the Fermi energy difference.

To investigate the methanol dehydrogenation activity, the coverage of adsorbed $\mathrm{CO}$ on $\mathrm{Pt}$ was measured from the methanol dehydrogenation reaction (eq 1). Wieckowski's group showed that the amount of $\mathrm{CO}_{\mathrm{ad}}$ formed from methanol decomposition can be measured without changing the electrolyte solution by combining chronoamperometry and fast-scan cyclic voltammetry $(\mathrm{CV})^{34,46,65}$ under potential control (Figure 1).

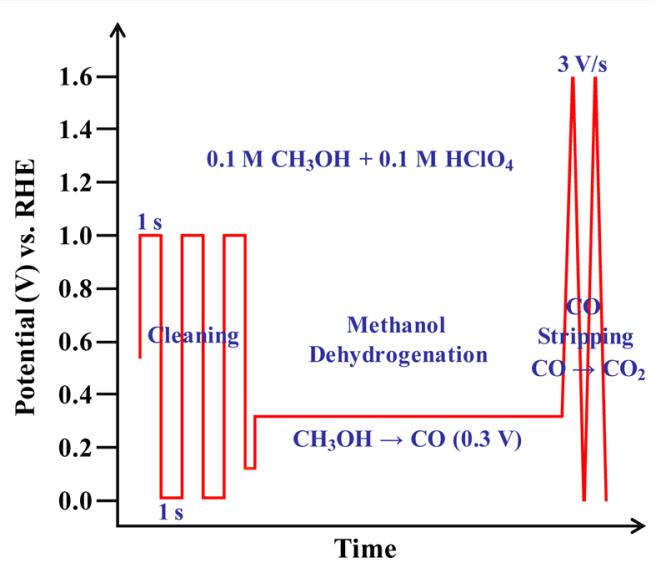

Figure 1. Schematic figure representing the potential control and the corresponding function of each step during methanol electrooxidation. The time for chronoamperometry (methanol dehydrogenation) is changed from 0.1 to $150 \mathrm{~s}$ to measure the $\mathrm{CO}$ coverage as a function of reaction time.

This technique consists of three steps, cleaning, methanol dehydrogenation, and CO stripping. During the chronoamperometry step, methanol is decomposed into $\mathrm{CO}$, which is strongly adsorbed on $\mathrm{Pt}$ until stripped through the fast-scan $\mathrm{CV}$. This is possible because at a fast scan rate, $\mathrm{Pt}$ is insensitive to the presence of methanol in the solution, and only the adsorbed $\mathrm{CO}$ is stripped during the fast $\mathrm{CV}$ (Figure 2).

The coverage of $\mathrm{CO}$ was measured by varying the chronoamperometry time $(0.1-150 \mathrm{~s})$. Previous research has shown that the rate of $\mathrm{CO}_{\mathrm{ad}}$ formation from methanol on a $\mathrm{Pt}$ surface can be modeled by the Elovich equation (eq 4), which assumes a linear dependence of the activation barrier for methanol dehydrogenation on $\mathrm{CO}$ coverage. ${ }^{6-69}$ Figure 3 shows the $\mathrm{CO}$ coverage behavior as a function of reaction time and is fitted by

$$
\frac{\mathrm{d} \theta_{\mathrm{CO}}}{\mathrm{d} t}=k_{\mathrm{a}} C_{\mathrm{m}} \exp \left(-\alpha \theta_{\mathrm{CO}}\right)
$$

where $k_{\mathrm{a}}$ is the rate constant for methanol dehydrogenation, $C_{\mathrm{m}}$ is the methanol concentration ( $0.1 \mathrm{M}$ in this experiment), and $\alpha$ reflects the effect of repulsive $\mathrm{CO}$ interactions on the rate of methanol dehydrogenation. The $\mathrm{CO}$ coverage was measured from the charges corresponding to the oxidation of the adsorbed $\mathrm{CO}$, which can be obtained by integrating the $\mathrm{CO}$ stripping peak of Figure 2 after background subtraction. 


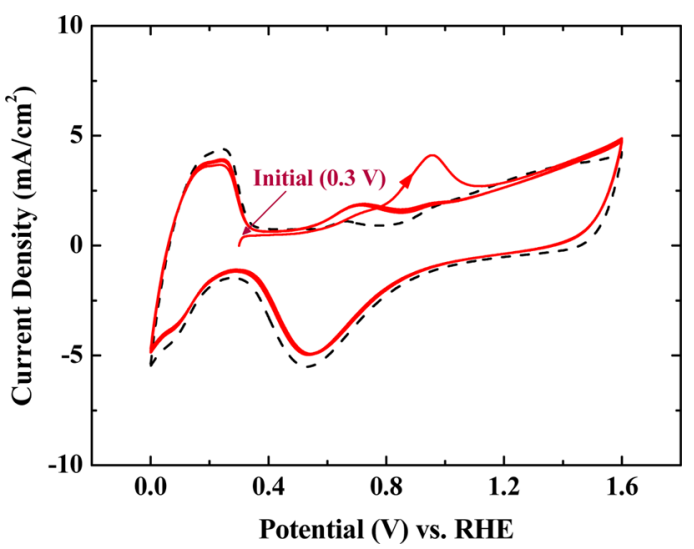

Figure 2. Fast scan $(3 \mathrm{~V} / \mathrm{s}) \mathrm{CV}$ of $\mathrm{Pt}$ showing the $\mathrm{CO}_{\mathrm{ad}}$ stripping peak (first cycle) and subsequent three cycles (total of four cycles), measured from potential control (Figure 1) in $0.1 \mathrm{M} \mathrm{HClO}_{4}+0.1$ $\mathrm{M} \mathrm{CH}_{3} \mathrm{OH}$ (red solid line). The second and subsequent scans are almost identical and also similar to the $\mathrm{CV}$ curve in $0.1 \mathrm{M} \mathrm{HClO}_{4}$ (dotted line), except for a slight current at around $0.7 \mathrm{~V}$ from the methanol decomposition process forming soluble species. ${ }^{46}$ Thus, the second scan of $\mathrm{CV}$ was used as a background to obtain the charge corresponding to the oxidation of $\mathrm{CO}_{\mathrm{ad}}$.

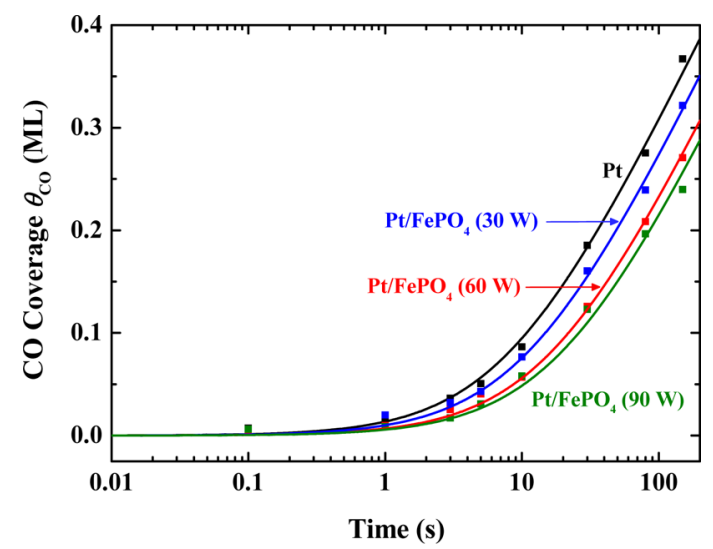

Figure 3. $\mathrm{CO}$ coverage versus time for each $\mathrm{Pt}$ surface prepared by different sputtering powers of $\mathrm{FePO}_{4}$. The $\mathrm{CO}_{\mathrm{ad}}$ coverage was obtained from a CV scan at the rate of $3 \mathrm{~V} / \mathrm{s}$ in $0.1 \mathrm{M} \mathrm{HClO}_{4}+0.1$ $\mathrm{M} \mathrm{CH}_{3} \mathrm{OH}$ (Figure 2) and fitted from eq 4.

With the initial condition of $\theta_{\mathrm{CO}}=0$ at $t=0$, we obtained the rate constant for methanol dehydrogenation of each sample. Before this process, we obtained $\alpha$ from each sample, and the average value of $\alpha$ was used to acquire a more reliable rate constant $k_{\mathrm{a}}$ for methanol dehydrogenation (see Figure S4, SI).

Figure 4 clearly exhibits the trend that the methanol dehydrogenation activity $k_{\mathrm{a}}$ decreases with the downshift of the d-band center (from the valence band spectra of Figure $\mathrm{S} 5, \mathrm{SI})$. On the $\mathrm{Pt}$ surface, the dissociative adsorption of methanol involving first-hydrogen extraction by $\mathrm{O}-\mathrm{H}$ or $\mathrm{C}-$ $\mathrm{H}$ bond scission is regarded as the rate-determining step of methanol dehydrogenation. ${ }^{16,70,71}$ Because the methanol desorption barrier is less than that for the $\mathrm{O}-\mathrm{H}$ or $\mathrm{C}-\mathrm{H}$ scission, ${ }^{70,72}$ methanol desorption is often observed on $\mathrm{Pt}$ surfaces in ultrahigh vacuum. ${ }^{73-75}$ From this point of view, a stronger adsorption of methanol on $\mathrm{Pt}$ may induce a higher methanol dehydrogenation rate by increasing the likelihood of $\mathrm{O}-\mathrm{H}$ or $\mathrm{C}-\mathrm{H}$ scission and finally lead to very stable $\mathrm{CO}_{\mathrm{ad}}$ through subsequent exothermic reactions. Therefore, the

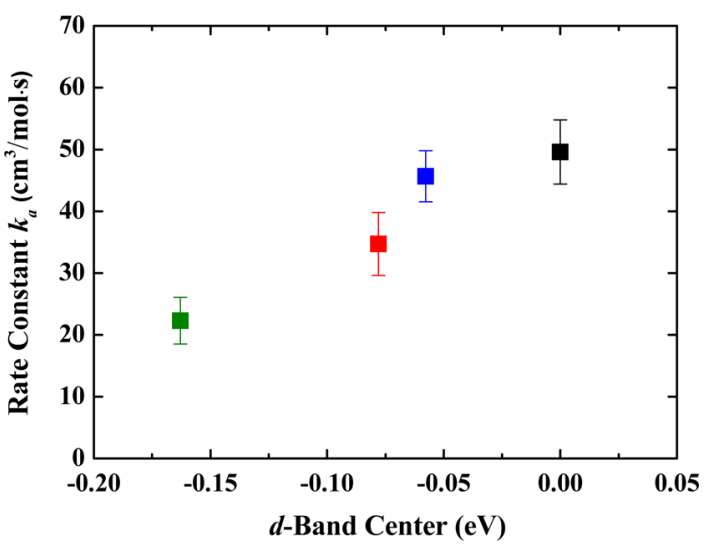

Figure 4. Rate constant for methanol dehydrogenation on $\mathrm{Pt}$ surfaces as a function of the d-band center, as measured from the valence band spectra in Figure S5 (SI) (relative to pure Pt).

decrease in the rate constant can originate from direct methanol desorption without bond scission and following catalytic reactions because the downshift of the d-band center implies a weaker adsorption of reactant molecules on the Pt. It should be noted that these kinds of arguments can be more systematically described when the changes of the activation barrier and the adsorption energy of each reaction step are calculated according to the d-band shift of Pt by considering the scaling properties in the adsorption energies of adsorbed reaction intermediates or by considering the BrønstedEvans-Polanyi relationships, which have been established between activation barriers and reaction energies for surface reactions. ${ }^{18,20,76-80}$

In addition, the higher position of the d-band center relative to the Fermi level not only results in the strong binding of a reactant on $\mathrm{Pt}$ but also the strong binding of spectator species in the electrolyte, such as specifically adsorbed anions, underpotentially deposited hydrogen $\left(\mathrm{H}_{\text {upd }}\right), \mathrm{OH}_{\mathrm{ad}}$, and other nonreactive molecular species that block the available $\mathrm{Pt}$ sites for methanol adsorption. ${ }^{24,41,81}$ Therefore, an optimum point of the reaction rate would exist at a suitable position of the d-band center, and the so-called volcano-type relation should appear. ${ }^{24}$ However, in this experiment, because we covered only the downshift of the d-band center, further study is needed on the region of the higher d-band center relative to pure Pt by opposite metalphosphate selection to establish the overall trend of methanol dehydrogenation.

In summary, to identify the electronic effect during a MOR, we separated the $\mathrm{CO}$ oxidation process by introducing an elaborate potential control. With this approach, we could systematically study the electronic effect on methanol dehydrogenation without concern for any unfavorable effects. We confirmed that the dehydrogenation activity of the $\mathrm{Pt}$ surface decreases with the downshift of the d-band center. Through further incorporation of $\mathrm{CO}$ oxidation properties or the bifunctional effect, advanced designs of methanol oxidation catalysts can be achieved. Also, this kind of potential control strategy can be applied to other catalytic reactions, such as ethanol oxidation or formic acid oxidation, to resolve otherwise-complicated catalytic reactions with the proper tuning of the electronic structure. 


\section{ASSOCIATED CONTENT}

\section{S Supporting Information}

Detailed experimental procedures, additional electrochemical analysis, structural characterizations, and XPS spectra. This material is available free of charge via the Internet at http:// pubs.acs.org.

\section{AUTHOR INFORMATION}

\section{Corresponding Author}

*E-mail: byungwoo@snu.ac.kr. Phone: +82-2-880-8319. Fax: +82-2-885-9671.

\section{Notes}

The authors declare no competing financial interest.

\section{ACKNOWLEDGMENTS}

This research was supported by the National Research Foundation of Korea, through the World Class University (WCU, R31-2008-000-10075-0) and the Korean Government (MEST:NRF, 2010-0029065).

\section{REFERENCES}

(1) Winter, M.; Brodd, R. J. What Are Batteries, Fuel Cells, and Supercapacitors? Chem. Rev. 2004, 104, 4245-4269.

(2) Steele, B. C. H.; Heinzel, A. Materials for Fuel-Cell Technologies. Nature 2001, 414, 345-352.

(3) Antolini, E. Catalysts for Direct Ethanol Fuel Cells. J. Power Sources 2007, 170, 1-12.

(4) Carrette, L.; Friedrich, K. A.; Stimming, U. Fuel CellsFundamentals and Applications. Fuel Cells 2001, 1, 5-39.

(5) Spendelow, J. S.; Wieckowski, A. Electrocatalysis of Oxygen Reduction and Small Alcohol Oxidation in Alkaline Media. Phys. Chem. Chem. Phys. 2007, 9, 2654-2675.

(6) Wang, C.-Y. Fundamental Models for Fuel Cell Engineering. Chem. Rev. 2004, 104, 4727-4766.

(7) Swider-Lyons, K. E.; Campbell, S. A. Physical Chemistry Research toward Proton Exchange Membrane Fuel Cell Advancement. J. Phys. Chem. Lett. 2013, 4, 393-401.

(8) Gasteiger, H. A.; Kocha, S. S.; Sompalli, B.; Wagner, F. T. Activity Benchmarks and Requirements for Pt, Pt-Alloy, and Non-Pt Oxygen Reduction Catalysts for PEMFCs. Appl. Catal., B 2005, 56, 9-35.

(9) Liu, H.; Song, C.; Zhang, L.; Zhang, J.; Wang, H.; Wilkinson, D. P. A Review of Anode Catalysis in the Direct Methanol Fuel Cell. J. Power Sources 2006, 155, 95-110.

(10) Wang, B. Recent Development of Non-Platinum Catalysts for Oxygen Reduction Reaction. J. Power Sources 2005, 152, 1-15.

(11) Kang, S.; Lee, J.; Lee, J. K.; Chung, S.-Y.; Tak, Y. Influence of Bi Modification of Pt Anode Catalyst in Direct Formic Acid Fuel Cells. J. Phys. Chem. B 2006, 110, 7270-7274.

(12) He, T.; Kreidler, E.; Xiong, L.; Ding, E. Combinatorial Screening and Nano-Synthesis of Platinum Binary Alloys for Oxygen Electroreduction. J. Power Sources 2007, 165, 87-91.

(13) Suntivich, J.; Xu, Z.; Carlton, C. E.; Kim, J.; Han, B.; Lee, S. W.; Bonnet, N.; Marzari, N.; Allard, L. F.; Gasteiger, H. A.; et al. Surface Composition Tuning of Au-Pt Bimetallic Nanoparticles for Enhanced Carbon Monoxide and Methanol Electro-Oxidation. J. Am. Chem. Soc. 2013, 135, 7985-7991.

(14) Hammer, B.; Nørskov, J. K. Electronic Factors Determining the Reactivity of Metal Surfaces. Surf. Sci. 1995, 343, 211-220.

(15) Pallassana, V.; Neurock, M.; Hansen, L. B.; Hammer, B.; Nørskov, J. K. Theoretical Analysis of Hydrogen Chemisorption on $\mathrm{Pd}(111), \operatorname{Re}(0001)$ and $\mathrm{Pd}_{\mathrm{ML}} / \operatorname{Re}(0001), \operatorname{Re}_{\mathrm{ML}} / \mathrm{Pd}(111)$ Pseudomorphic Overlayers. Phys. Rev. B 1999, 60, 6146-6154.

(16) Greeley, J.; Nørskov, J. K.; Mavrikakis, M. Electronic Structure and Catalysis on Metal Surfaces. Annu. Rev. Phys. Chem. 2002, 53, 319-348.
(17) Nilsson, A.; Pettersson, L. G. M.; Hammer, B.; Bligaard, T.; Christensen, C. H.; Nørskov, J. K. The Electronic Structure Effect in Heterogeneous Catalysis. Catal. Lett. 2005, 100, 111-114.

(18) Nørskov, J. K.; Bligaard, T.; Rossmeisl, J.; Christensen, C. H. Toward the Computational Design of Solid Catalysts. Nat. Chem. 2009, 1, 37-46.

(19) Jiang, T.; Mowbray, D. J.; Dobrin, S.; Falsig, H.; Hvolbaek, B.; Bligaard, T.; Nørskov, J. K. Trends in CO Oxidation Rates for Metal Nanoparticles and Close-Packed, Stepped, and Kinked Surfaces. J. Phys. Chem. C 2009, 113, 10548-10553.

(20) Nørskov, J. K.; Abild-Pedersen, F.; Studt, F.; Bligaard, T. Density Functional Theory in Surface Chemistry. Proc. Natl. Acad. Sci. U.S.A. 2011, 108, 937-943.

(21) Kibler, L. A.; El-Aziz, A. M.; Hoyer, R.; Kolb, D. M. Tuning Reaction Rates by Lateral Strain in a Palladium Monolayer. Angew. Chem., Int. Ed. 2005, 44, 2080-2084.

(22) Lima, F. H. B.; Zhang, J.; Shao, M. H.; Sasaki, K.; Vukmirovic, M. B.; Ticianelli, E. A.; Adzic, R. R. Catalytic Activity-d-Band Center Correlation for the $\mathrm{O}_{2}$ Reduction Reaction on Platinum in Alkaline Solutions. J. Phys. Chem. C 2007, 111, 404-410.

(23) Stamenkovic, V.; Mun, B. S.; Mayrhofer, K. J. J.; Ross, P. N.; Markovic, N. M.; Rossmeisl, J.; Greeley, J.; Nørskov, J. K. Changing the Activity of Electrocatalysts for Oxygen Reduction by Tuning the Surface Electronic Structure. Angew. Chem., Int. Ed. 2006, 45, 28972901.

(24) Stamenkovic, V. R.; Mun, B. S.; Arenz, M.; Mayrhofer, K. J. J.; Lucas, C. A.; Wang, G.; Ross, P. N.; Markovic, N. M. Trends in Electrocatalysis on Extended and Nanoscale Pt-Bimetallic Alloy Surfaces. Nat. Mater. 2007, 6, 241-247.

(25) Stamenkovic, V. R.; Fowler, B.; Mun, B. S.; Wang, G.; Ross, P. N.; Lucas, C. A.; Markovic, N. M. Improved Oxygen Reduction Activity on $\mathrm{Pt}_{3} \mathrm{Ni}(111)$ via Increased Surface Site Availability. Science 2007, 315, 493-497.

(26) Toyoda, E.; Jinnouchi, R.; Hatanaka, T.; Morimoto, Y.; Mitsuhara, K.; Visikovskiy, A.; Kido, Y. The d-Band Structure of Pt Nanoclusters Correlated with the Catalytic Activity for Oxygen Reduction Reaction. J. Phys. Chem. C 2011, 115, 21236-21240.

(27) Yoo, S.; Kim, S.-K.; Jeon, T.-Y.; Hwang, S.; Lee, J.-G.; Lee, S.C.; Lee, K.-S.; Cho, Y.-H.; Sung, Y.-E.; Lim, T.-H. Enhanced Stability and Activity of $\mathrm{Pt}-\mathrm{Y}$ Alloy Catalysts for Electrocatalytic Oxygen Reduction. Chem. Commun. 2011, 47, 11414-11416.

(28) Yoo, S.; Hwang, S.; Lee, J.-G.; Lee, S.-C.; Lim, T.-H.; Sung, Y.E.; Wieckowski, A.; Kim, S.-K. Promoting Effects of La for Improved Oxygen Reduction Activity and High Stability of Pt on Pt-La Alloy Electrodes. Energy Environ. Sci. 2012, 5, 7521-7525.

(29) Hwang, S.; Kim, S.-K.; Lee, J.-G.; Lee, S.-C.; Jang, J.; Kim, P.; Lim, T.-H.; Sung, Y.-E.; Yoo, S. Role of Electronic Perturbation in Stability and Activity of Pt-Based Alloy Nanocatalysts for Oxygen Reduction. J. Am. Chem. Soc. 2012, 134, 19508-19511.

(30) Iwasita, T. Electrocatalysis of Methanol Oxidation. Electrochim. Acta 2002, 47, 3663-3674.

(31) Gasteiger, H. A.; Markovic, N.; Ross, P. N.; Cairns, E. J. Methanol Electrooxidation on Well-Characterized Pt-Ru Alloys. J. Phys. Chem. 1993, 97, 12020-12029.

(32) Watanabe, M.; Motoo, S. Electrocatalysis by Ad-Atoms: Part III. Enhancement of the Oxidation of Carbon Monoxide on Platinum by Ruthenium Ad-Atoms. J. Electroanal. Chem. 1975, 60, 275-283.

(33) Swathirajan, S.; Mikhail, Y. M. Electrochemical Oxidation of Methanol at Chemically Prepared Platinum-Ruthenium Alloy Electrodes. J. Electrochem. Soc. 1991, 138, 1321-1326.

(34) Cao, D.; Lu, G.-Q.; Wieckowski, A.; Wasileski, S. A.; Neurock, M. Mechanisms of Methanol Decomposition on Platinum: A Combined Experimental and Ab Initio Approach. J. Phys. Chem. B 2005, 109, 11622-11633.

(35) Parsons, R.; Vandernoot, T. The Oxidation of Small Organic Molecules: A Survey of Recent Fuel Cell Related Research. J. Electroanal. Chem. 1988, 257, 9-45. 
(36) Capon, A.; Parsons, R. The Oxidation of Formic Acid at Noble Metal Electrodes: Part III. Intermediates and Mechanism on Platinum Electrodes. J. Electroanal. Chem. 1973, 45, 205-231.

(37) Batista, E. A.; Malpass, G. R. P.; Motheo, A. J.; Iwasita, T. New Insight into the Pathways of Methanol Oxidation. Electrochem. Commun. 2003, 5, 843-846.

(38) Herrero, E.; Chrzanowski, W.; Wieckowski, A. Dual Path Mechanism in Methanol Electrooxidation on a Platinum Electrode. J. Phys. Chem. 1995, 99, 10423-10424.

(39) Sriramulu, S.; Jarvi, T. D.; Stuve, E. M. Reaction Mechanism and Dynamics of Methanol Electrooxidation on Platinum(111). J. Electroanal. Chem. 1999, 467, 132-142.

(40) Cuesta, A. At Least Three Contiguous Atoms Are Necessary for CO Formation during Methanol Electrooxidation on Platinum. J. Am. Chem. Soc. 2006, 128, 13332-13333.

(41) Markovic, N. M.; Ross, P. N. Surface Science Studies of Model Fuel Cell Electrocatalysts. Surf. Sci. Rep. 2002, 45, 117-229.

(42) Evarts, S. E.; Kendrick, I.; Wallstrom, B. L.; Mion, T.; Abedi, M.; Dimakis, N.; Smotkin, E. S. Ensemble Site Requirements for Oxidative Adsorption of Methanol and Ethanol on Pt Membrane Electrode Assemblies. ACS Catal. 2012, 2, 701-707.

(43) Tritsaris, G. A.; Rossmeisl, J. Methanol Oxidation on Model Elemental and Bimetallic Transition Metal Surfaces. J. Phys. Chem. C 2012, 116, 11980-11986.

(44) Lu, C.; Rice, C.; Masel, R. I.; Babu, P. K.; Waszczuk, P.; Kim, H. S.; Oldfield, E.; Wieckowski, A. UHV, Electrochemical NMR, and Electrochemical Studies of Platinum/Ruthenium Fuel Cell Catalysts. J. Phys. Chem. B 2002, 106, 9581-9589.

(45) Spendelow, J. S.; Babu, P. K.; Wieckowski, A. Electrocatalytic Oxidation of Carbon Monoxide and Methanol on Platinum Surfaces Decorated with Ruthenium. Curr. Opin. Solid State Mater. 2005, 9, $37-48$.

(46) Lu, G.-Q.; Chrzanowski, W.; Wieckowski, A. Catalytic Methanol Decomposition Pathways on a Platinum Electrode. J. Phys. Chem. B 2000, 104, 5566-5572.

(47) Iwasita, T.; Xia, X. H.; Liess, H.-D.; Vielstich, W. Electrocatalysis of Organic Oxidations: Influence of Water Adsorption on the Rate of Reaction. J. Phys. Chem. B 1997, 101, $7542-7547$.

(48) Markovic, N. M.; Gasteiger, H. A.; Ross, P. N.; Jiang, X.; Villegas, I.; Weaver, M. J. Electro-Oxidation Mechanisms of Methanol and Formic Acid on $\mathrm{Pt}-\mathrm{Ru}$ Alloy Surfaces. Electrochim. Acta 1995, 40, 91-98.

(49) Vielstich, W.; Lamm, A.; Gasteiger, H. A. Handbook of Fuel Cells; John Wiley \& Sons Ltd.: New York, 2003; Vol. 2: Electrocatalysis.

(50) Cheetham, A. K.; Ferey, G.; Loiseau, T. Open-Framework Inorganic Materials. Angew. Chem., Int. Ed. 1999, 38, 3268-3292.

(51) Lee, B.; Kim, C.; Park, Y.; Kim, T.-G.; Park, B. Nanostructured Platinum/Iron-Phosphate Thin-Film Electrodes for Methanol Oxidation. Electrochem. Solid-State Lett. 2006, 9, E27-E30.

(52) Kim, C.; Lee, B.; Park, Y.; Park, B.; Lee, J.; Kim, H. IronPhosphate/Platinum/Carbon Nanocomposites for Enhanced Electrocatalytic Stability. Appl. Phys. Lett. 2007, 91, 113101.

(53) Park, Y.; Lee, B.; Kim, C.; Kim, J.; Nam, S.; Oh, Y.; Park, B. Modification of Gold Catalysis with Aluminum Phosphate for Oxygen-Reduction Reaction. J. Phys. Chem. C 2010, 114, 3688-3692.

(54) Cho, J.; Kim, Y.-W.; Kim, B.; Lee, J.-G.; Park, B. A Breakthrough in the Safety of Lithium Secondary Batteries by Coating the Cathode Material with $\mathrm{AlPO}_{4}$ Nanoparticles. Angew. Chem., Int. Ed. 2003, 42, 1618-1621.

(55) Park, Y.; Nam, S.; Oh, Y.; Choi, H.; Park, J.; Park, B. Electrochemical Promotion of Oxygen Reduction on Gold with Aluminum-Phosphate Overlayer. J. Phys. Chem. C 2011, 115, 70927096.

(56) Bouwman, P. J.; Dmowski, W.; Stanley, J.; Cotten, G. B.; Swider-Lyons, K. E. Platinum-Iron Phosphate Electrocatalysts for Oxygen Reduction in PEMFCs. J. Electrochem. Soc. 2004, 151, A1989-A1998.
(57) Shao, M.; Peles, A.; Shoemaker, K. Electrocatalysis on Platinum Nanoparticles: Particle Size Effect on Oxygen Reduction Reaction Activity. Nano Lett. 2011, 11, 3714-3719.

(58) Watanabe, M.; Saegusa, S.; Stonehart, P. High Platinum Electrocatalyst Utilizations for Direct Methanol Oxidation. J. Electroanal. Chem. 1989, 271, 213-220.

(59) Frelink, T.; Visscher, W.; Veen, J. A. R. V. Particle Size Effect of Carbon-Supported Platinum Catalysts for the Electrooxidation of Methanol. J. Electroanal. Chem. 1995, 382, 65-72.

(60) Giordano, N.; Passalacqua, E.; Pino, L.; Arico, A. S.; Antonucci, V.; Vivaldi, M.; Kinoshita, K. Analysis of Platinum Particle Size and Oxygen Reduction in Phosphoric Acid. Electrochim. Acta 1991, 36, 1979-1984.

(61) Sattler, M. L.; Ross, P. N. The Surface Structure of Pt Crystallites Supported on Carbon Black. Ultramicroscopy 1986, 20, $21-28$.

(62) Peuckert, M.; Yoneda, T.; Betta, R. A. D.; Boudart, M. Oxygen Reduction on Small Supported Platinum Particles. J. Electrochem. Soc. 1986, 133, 944-947.

(63) Kinoshita, K. Particle Size Effects for Oxygen Reduction on Highly Dispersed Platinum in Acid Electrolytes. J. Electrochem. Soc. 1990, 137, 845-848.

(64) Sheng, W.; Chen, S.; Vescovo, E.; Shao-Horn, Y. Size Influence on the Oxygen Reduction Reaction Activity and Instability of Supported Pt Nanoparticles. J. Electrochem. Soc. 2012, 159, B96B103.

(65) Lu, G.-Q.; Crown, A.; Wieckowski, A. Formic Acid Decomposition on Polycrystalline Platinum and Palladized Platinum Electrodes. J. Phys. Chem. B 1999, 103, 9700-9711.

(66) Spendelow, J. S.; Goodpaster, J. D.; Kenis, P. J. A.; Wieckowski, A. Methanol Dehydrogenation and Oxidation on $\mathrm{Pt}(111)$ in Alkaline Solutions. Langmuir 2006, 22, 10457-10464.

(67) Bagotzky, V. S.; Vassiliev, Y. B. Adsorption of Organic Substances on Platinum Electrodes. Electrochim. Acta 1966, 11, $1439-1461$.

(68) Seiler, T.; Savinova, E. R.; Friedrich, K. A.; Stimming, U. Poisoning of $\mathrm{PtRu} / \mathrm{C}$ Catalysts in the Anode of a Direct Methanol Fuel Cell: A DEMS Study. Electrochim. Acta 2004, 49, 3927-3936.

(69) Khazova, O. A.; Mikhailova, A. A.; Skundin, A. M.; Tuseeva, E. K.; Havranek, A.; Wippermann, K. Kinetics of Methanol Oxidation on Supported and Unsupported $\mathrm{Pt} / \mathrm{Ru}$ Catalysts Bonded to PEM. Fuel Cells 2002, 2, 99-108.

(70) Greeley, J.; Mavrikakis, M. A First-Principles Study of Methanol Decomposition on $\operatorname{Pt}(111)$. J. Am. Chem. Soc. 2002, 124, 7193-7201.

(71) Ferrin, P.; Mavrikakis, M. Structure Sensitivity of Methanol Electrooxidation on Transition Metals. J. Am. Chem. Soc. 2009, 131, 14381-14389.

(72) Desai, S. K.; Neurock, M.; Kourtakis, K. A Periodic Density Functional Theory Study of the Dehydrogenation of Methanol over Pt(111). J. Phys. Chem. B 2002, 106, 2559-2568.

(73) Gibson, K. D.; Dubois, L. H. Step Effects in the Thermal Decomposition on Methanol on Pt(111). Surf. Sci. 1990, 233, 5964.

(74) Sexton, B. A. Methanol Decomposition on Platinum (111). Surf. Sci. 1981, 102, 271-281.

(75) Ehlers, D. H.; Spitzer, A.; Lüth, H. The Adsorption of Methanol on $\mathrm{Pt}(111)$, An IR Reflection and UV Photoemission Study. Surf. Sci. 1985, 160, 57-69.

(76) Abild-Pedersen, F.; Greeley, J.; Studt, F.; Rossmeisl, J.; Munter, T. R.; Moses, P. G.; Skulason, E.; Bligaard, T.; Nørskov, J. K. Scaling Properties of Adsorption Energies for HydrogenContaining Molecules on Transition-Metal Surfaces. Phys. Rev. Lett. 2007, 99, 016105.

(77) Wang, S.; Petzold, V.; Tripkovic, V.; Kleis, J.; Howalt, J. G.; Skúlason, E.; Fernández, E. M.; Hvolbaek, B.; Jones, G.; Toftelund, A.; et al. Universal Transition State Scaling Relations for (De)hydrogenation over Transition Metals. Phys. Chem. Chem. Phys. 2011, 13, 20760-20765. 
(78) Sutton, J. E.; Vlachos, D. G. A Theoretical and Computational Analysis of Linear Free Energy Relations for the Estimation of Activation Energies. ACS Catal. 2012, 2, 1624-1634.

(79) Michaelides, A.; Liu, Z.-P.; Zhang, C. J.; Alavi, A.; King, D. A.; $\mathrm{Hu}$, P. Identification of General Linear Relationships between Activation Energies and Enthalpy Changes for Dissociation Reactions at Surfaces. J. Am. Chem. Soc. 2003, 125, 3704-3705.

(80) Mehmood, F.; Rankin, R. B.; Greeley, J.; Curtiss, L. A. Trends in Methanol Decomposition on Transition Metal Alloy Clusters from Scaling and Brønsted-Evans-Polanyi Relationships. Phys. Chem. Chem. Phys. 2012, 14, 8644-8652.

(81) Kita, H.; Gao, Y.; Nakato, T.; Hattori, H. Effect of Hydrogen Sulphate Ion on the Hydrogen Ionization and Methanol Oxidation Reactions on Platinum Single-Crystal Electrodes. J. Electroanal. Chem. 1994, 373, 177-183. 


\title{
Supporting Information
}

\section{Electronic Effect in Methanol Dehydrogenation on Pt Surfaces: Potential Control during Methanol Electrooxidation}

\author{
Joonhyeon Kang, Seunghoon Nam, Yuhong Oh, Hongsik Choi, Sungun Wi, Byungho Lee, \\ Taehyun Hwang, Saeromi Hong, and Byungwoo Park* \\ WCU Hybrid Materials Program, Department of Materials Science and Engineering, \\ Research Institute of Advanced Materials, \\ Seoul National University, Seoul 151-744, Korea
}

\section{Experimental Procedure}

$\mathrm{Pt} / \mathrm{FePO}_{4}$ nanocomposite electrodes were fabricated by rf magnetron co-sputtering on indium-tin oxide (ITO) glass using $\mathrm{Pt}$ and $\mathrm{FePO}_{4}$ targets at room temperature (RT) by varying the sputtering rate of $\mathrm{FePO}_{4}$ at a fixed power of $\mathrm{Pt}$. Thin films were annealed at $300^{\circ} \mathrm{C}$ for 30 min to enhance their adhesion onto the ITO surface as well as to synthesize well-connected Pt nanocrystals in the amorphous $\mathrm{FePO}_{4}$ matrix.

X-ray diffraction (XRD, New D8 Advance: Brucker) was used to characterize the crystal structures of $\mathrm{Pt}, \mathrm{Pt} / \mathrm{FePO}_{4}$ and $\mathrm{FePO}_{4}$, and to determine the grain size of $\mathrm{Pt}$ in the nanocomposite. The electronic structure of the Pt valence-band was analyzed by $\mathrm{x}$-ray photoelectron spectroscopy (XPS, AXIS-HSI: KRATOS) with 1253.84-eV incident photon.

\footnotetext{
* E-mail: byungwoo@snu.ac.kr. Phone: +82-2-880-8319. Fax: +82-2-885-9671.
} 
The Shirley background was subtracted from each measured spectrum, and the position of the $d$-band center was obtained from $\int N(\varepsilon) \varepsilon \mathrm{d} \varepsilon / \int N(\varepsilon) \mathrm{d} \varepsilon$, where $N(\varepsilon)$ is the density of states or the XPS intensity after background correction [1-6].

The $\mathrm{Pt} / \mathrm{FePO}_{4}$ nanocomposite, $\mathrm{Pt}$ wire, and $\mathrm{Hg} / \mathrm{Hg}_{2} \mathrm{Cl}_{2}$ (SCE) as the working, counter, and reference electrodes, respectively, were used with a computer-controlled potentiostat (CHI 604A: CH Instrumental Inc.). All of the potentials in this article were converted to RHE. The cyclic voltammetry (CV) was carried out in a $0.1 \mathrm{M} \mathrm{HClO}_{4}$ solution at a scan rate of $50 \mathrm{mV} / \mathrm{s}$, to determine the available $\mathrm{Pt}$ sites by integrating the hydrogen adsorption/desorption curves and to confirm the surface orientation of $\mathrm{Pt}$. For the CO-coverage measurement, a set of programmed potential steps, chronoamperometry, and fast-scan $\mathrm{CV}$ (Fig. 1) were performed in a $0.1 \mathrm{M} \mathrm{CH}_{3} \mathrm{OH}+0.1 \mathrm{M} \mathrm{HClO}_{4}$ solution. The potential steps for cleaning the Pt surfaces were attained by several $1.0 \mathrm{~V}$ (oxidation) $-0.01 \mathrm{~V}$ (reduction) steps with 1-s holding time for each step. Time for chronoamperometry (methanol dehydrogenation) was varied in the range of $0.1-150 \mathrm{~s}$ to measure the amount of adsorbed $\mathrm{CO}$ at different reaction times. Fast $\mathrm{CV}$ was performed at a scan rate of $3 \mathrm{~V} / \mathrm{s}$ to strip the $\mathrm{CO}_{\mathrm{ad}}$. Each electrochemical measurement was carried out in a $\mathrm{N}_{2}$-purged solution at RT. 


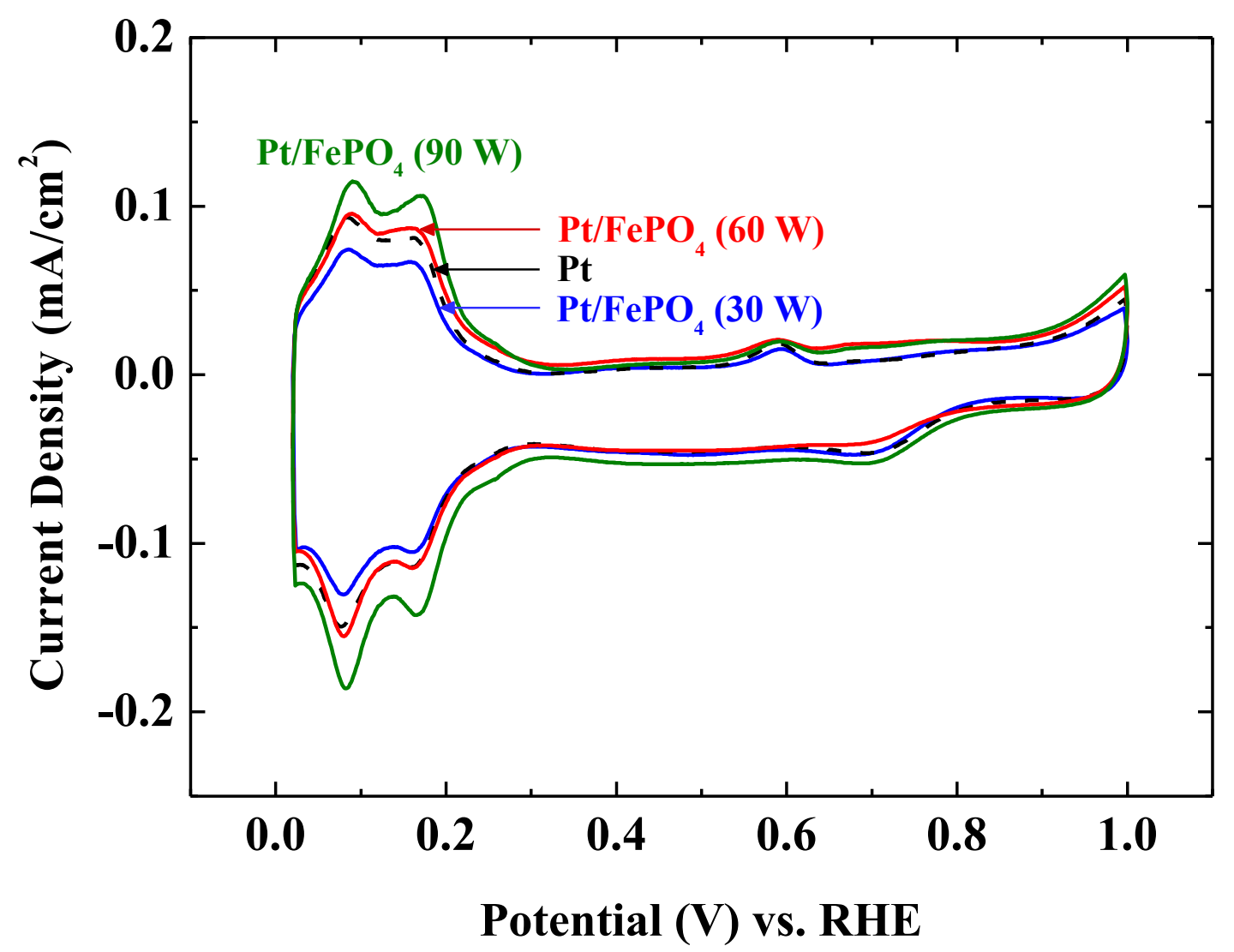

Fig. S1. Cyclic voltammograms of the $\mathrm{Pt}$ and $\mathrm{Pt} / \mathrm{FePO}_{4}$-nanocomposite electrodes with various sputtering powers of $\mathrm{FePO}_{4}$ in $0.1 \mathrm{M} \mathrm{HClO}_{4}$. 


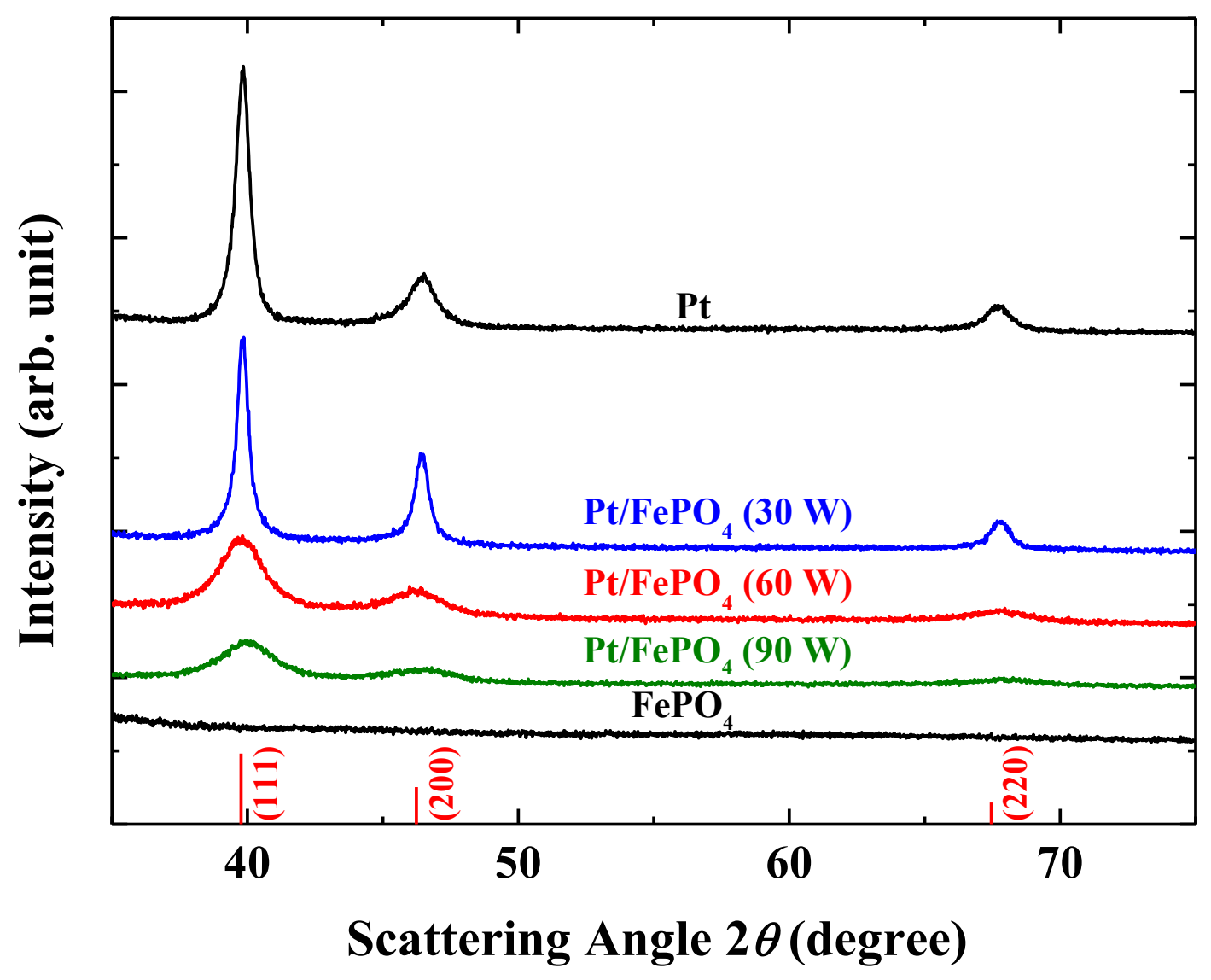

Fig. S2. X-ray diffraction of $\mathrm{Pt}$ and $\mathrm{Pt} / \mathrm{FePO}_{4}$ nanocomposites to determine the grain size of Pt nanocrystals from the $\Delta k$ vs. $k$ plot. 


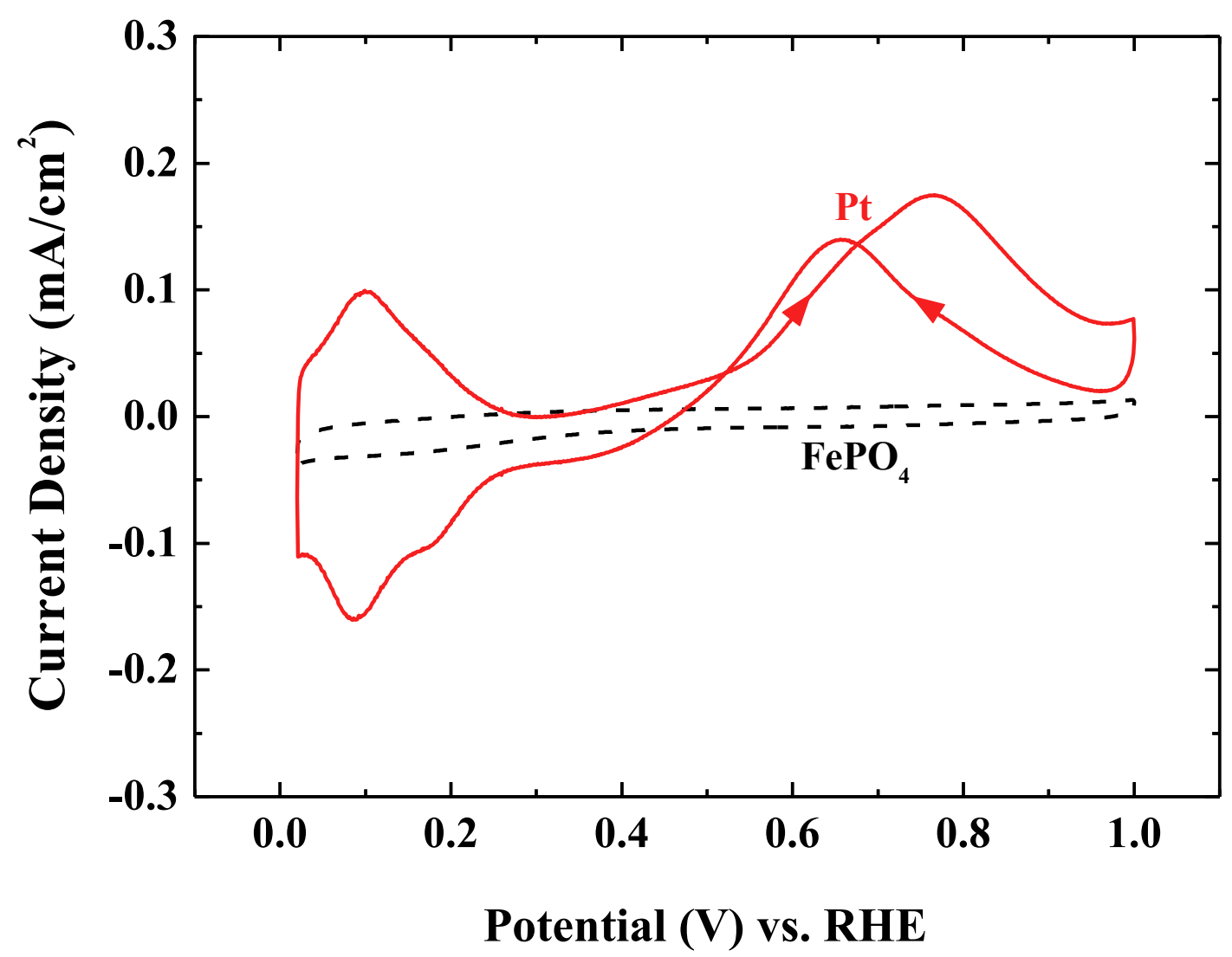

Fig. S3. Cyclic voltammograms of $\mathrm{Pt}$ and $\mathrm{FePO}_{4}$ in $0.1 \mathrm{M} \mathrm{HClO}_{4}+0.1 \mathrm{M} \mathrm{CH}_{3} \mathrm{OH}$ at a scan rate of $50 \mathrm{mV} / \mathrm{s}$. 


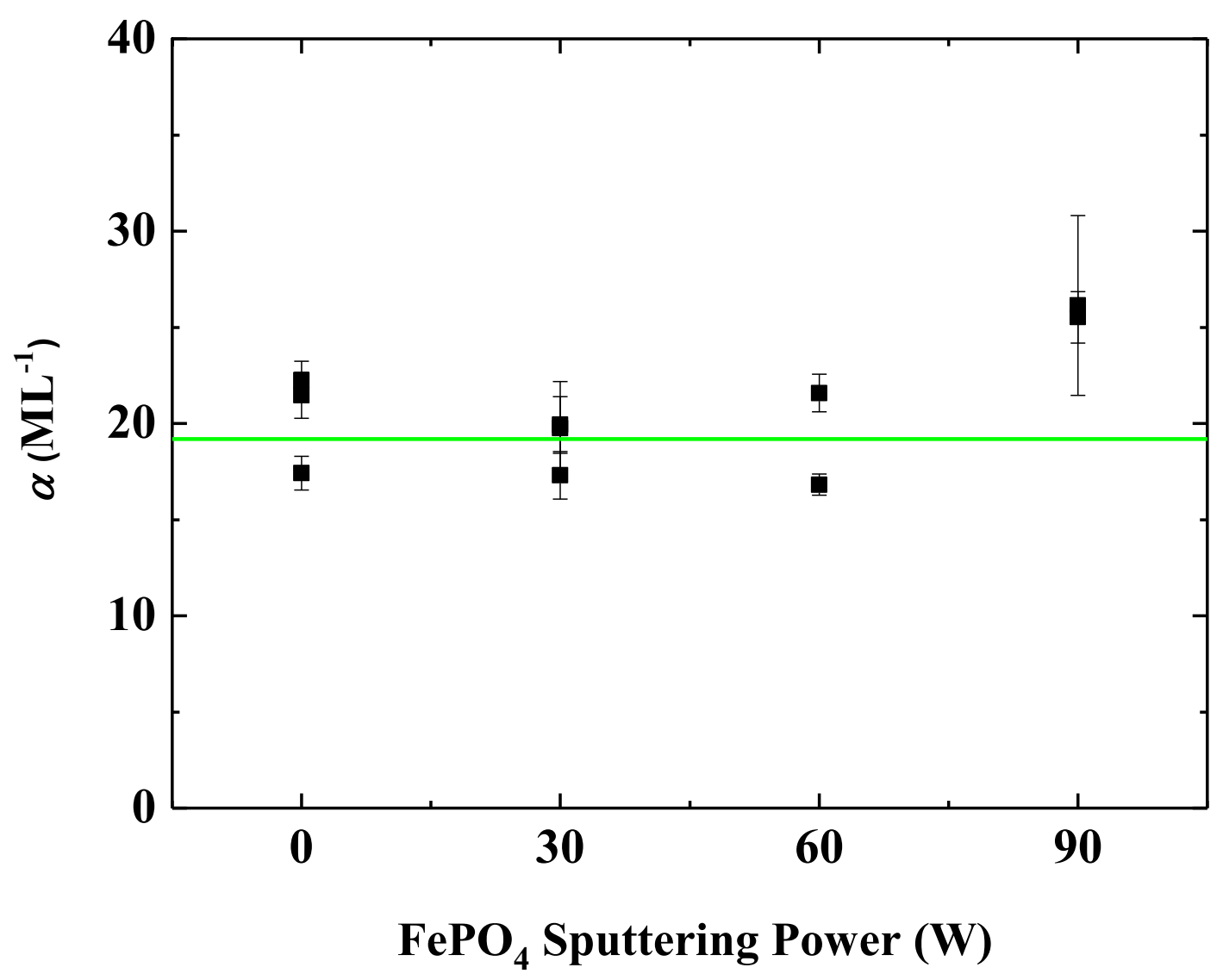

Fig. S4. Plot of $\alpha$ as a function of $\mathrm{FePO}_{4}$ sputtering power. In Eq. (4), $\alpha$ reflects the effect of repulsive $\mathrm{CO}$ interactions on the rate of methanol dehydrogenation; we did not find any considerable variations or tendency in $\alpha$ for different samples. So, $\alpha$ was obtained from each data, and the average value of $\alpha\left(19.2 \pm 0.9 \mathrm{ML}^{-1}\right)$ was used to obtain the rate constant $k_{a}$ for methanol dehydrogenation with the fitting from Fig. 3. 


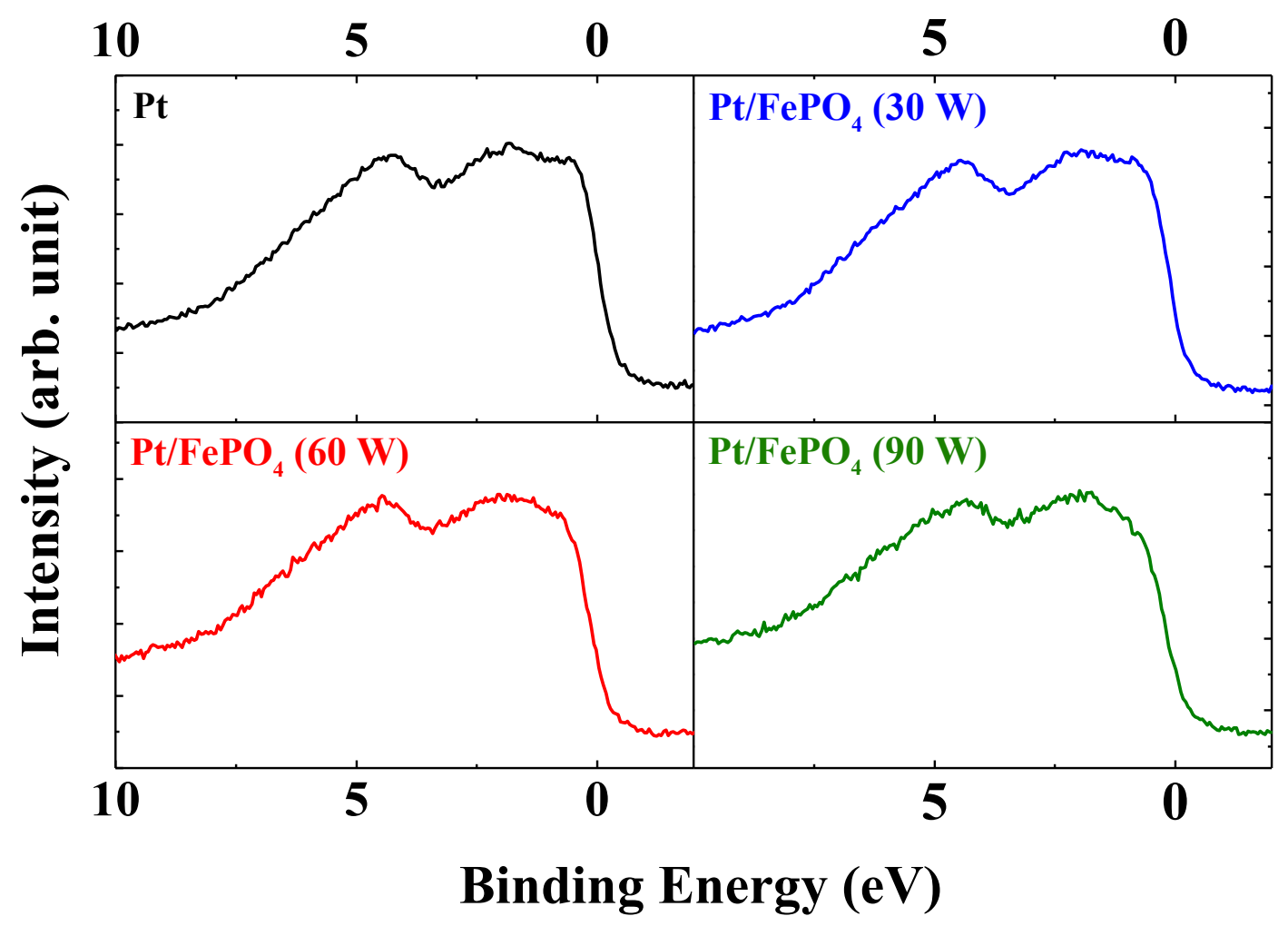

Fig. S5. The valence-band spectra for $\mathrm{Pt}$ and $\mathrm{Pt} / \mathrm{FePO}_{4}$ composites with various sputtering powers of $\mathrm{FePO}_{4}$. 


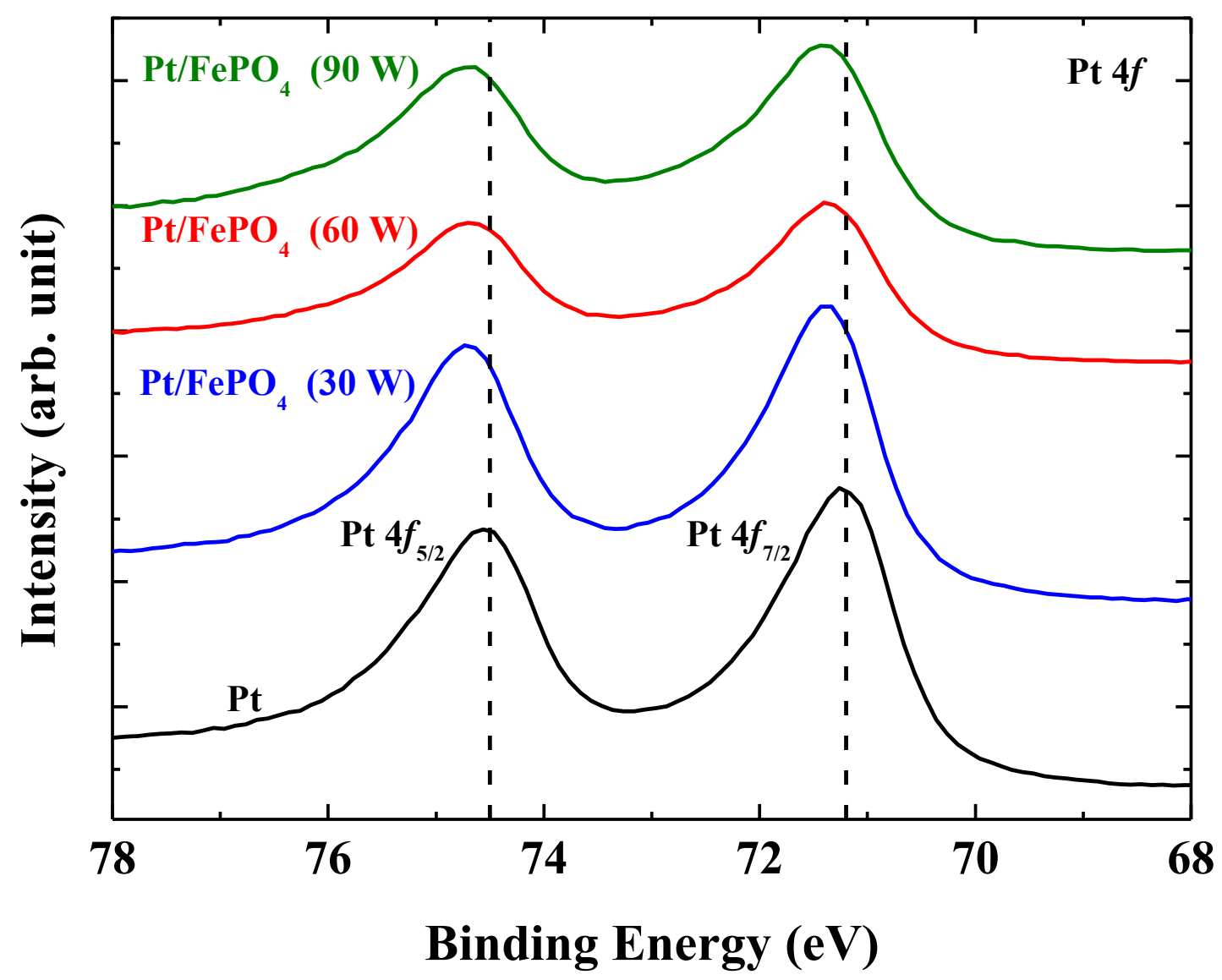

Fig. S6. XPS spectra in the $\mathrm{Pt} 4 f$ region for the $\mathrm{Pt}$ and $\mathrm{Pt} / \mathrm{FePO}_{4}$ nanocomposites with various sputtering powers of $\mathrm{FePO}_{4}$. The peak positions of pure $\mathrm{Pt}$ are represented by dashed lines, and the peak shift in the nanocomposites is clearly toward higher binding energies. 


\section{References}

(1) Shirley, D. A. High-Resolution X-Ray Photoemission Spectrum of the Valence Bands of Gold. Phys. Rev. B 1972, 5, 4709-4714.

(2) Stamenkovic, V. R.; Mun, B. S.; Arenz, M.; Mayrhofer, K. J. J.; Lucas, C. A.; Wang, G.; Ross, P. N.; Markovic, N. M. Trends in Electrocatalysis on Extended and Nanoscale Pt-Bimetallic Alloy Surfaces. Nat. Mater. 2007, 6, 241-247.

(3) Stamenkovic, V. R.; Fowler, B.; Mun, B. S.; Wang, G.; Ross, P. N.; Lucas, C. A.; Markovic, N. M. Improved Oxygen Reduction Activity on $\mathrm{Pt}_{3} \mathrm{Ni}(111)$ via Increased Surface Site Availability. Science 2007, 315, 493-497.

(4) You, S.; Kim, S.-K.; Jeon, T.-Y.; Hwang, S.; Lee, J.-G.; Lee, S.-C.; Lee, K.-S.; Cho, Y.-H.; Sung, Y.-E.; Lim, T.-H. Enhanced Stability and Activity of Pt-Y Alloy Catalysts for Electrocatalytic Oxygen Reduction. Chem. Comm. 2011, 47, 11414-11416.

(5) You, S.; Hwang, S.; Lee, J.-G.; Lee, S.-C.; Lim, T.-H.; Sung, Y.-E.; Wieckowski, A.; Kim, S.-K. Promoting Effects of La for Improved Oxygen Reduction Activity and High Stability of Pt on Pt-La Alloy Electrodes. Energy Environ. Sci. 2012, 5, 7521-7525.

(6) Hwang, S.; Kim, S.-K.; Lee, J.-G.; Lee, S.-C.; Jang, J.; Kim, P.; Lim, T.-H.; Sung, Y.-E.; Yoo, S. Role of Electronic Perturbation in Stability and Activity of Pt-Based Alloy Nanocatalysts for Oxygen Reduction. J. Am. Chem. Soc. 2012, 134, 19508-19511. 